\title{
El manejo del agua en la cuenca inferior de Miriguaca (Antofagasta de la Sierra): diseño de red y tecnologías hidráulicas prehispánicas
}

\section{Lorena Grana*, Marcos Quesada ** y Leticia Gasparotti* **}

\section{Resumen}

En este trabajo se presentan nuevas evidencias sobre las tecnologías paleohidráulicas de la red de riego de Miriguaca 1(MS1) localizada en Antofagasta de la Sierra (Catamarca). Estas evidencias permiten profundizar sobre las interpretaciones del funcionamiento y los diseños hidráulicos de las redes conocidas hasta el momento en la Puna meridional argentina. A través de análisis de imágenes satelitales y de controles pedestres se logró identificar una gran cantidad de campos de cultivo y canales e incluso sus modificaciones. También se detectó el uso de una represa de riego, la cual constituye la primera evidencia de esta naturaleza para la Puna meridional. Este dispositivo hídrico habría permitido la acumulación de agua para una mayor extensión de riego y un control sobre el tiempo para el uso del agua. En base al material arqueológico vinculado a la red de riego y su diseño se discute la cronología de su construcción y sus modos de uso.

Water management in the lower Miriguaca Basin (Antofagasta de
la Sierra): network design and Pre-Hispanic hydraulic technologies

\begin{abstract}
In this article, we present new evidence focussing on the palaeo-hydraulic technologies from the Miriguaca 1 (MS1) irrigation network, located in Antofagasta de la Sierra (Catamarca). These new data contribute to the current interpretations on the functioning and hydraulic design of these networks in the southern Argentine Puna. An analysis of satellite imagery coupled with field-testing, allowed us to recognize a large number of crop fields and channels, including their later modifications. We also describe a water dam used for irrigation, the first one for the southern Puna. This hydraulic structure would have allowed water storage, thereby enabling the development of a more extensive irrigation network, as well as better control for the use of water over time. Finally, we used the archaeological material remains recovered in association with the irrigation network, and its design, to propose a chronology of its construction and use.
\end{abstract}

* Instituto de Datación y Arqueometría (InDyA), CONICET - Provincia de Jujuy - Universidad Nacional de Jujuy (UNJu) - Universidad Nacional de Tucumán (UNT). Juan Bautista Alberdi 47 (CP Y46ooDTA) San Salvador de Jujuy, Jujuy. E-mail: lorenaggrana@yahoo.com.ar

** Centro de Investigaciones y Transferencia de Catamarca (CITCa), Universidad Nacional de Catamarca (UNCa) - CONICET. Prado 366 (CP K470oBDH). San Fernando del Valle de Catamarca, Catamarca, Argentina.

E-mail:mkesada@yahoo.com.ar; Igasparotti@arqueo.unca.edu.ar
Recibido:

6 de marzo de 2018

Aceptado:

12 de septiembre de 2018

\section{Palabras clave}

\section{Redes de riego}

Represa

Puna

\section{Keywords}

Irrigation networks Water dam

Puna 
1. Olivera (1992) establece para la región tres grandes sectores definidos por diferencia altitudinales en relación a los recursos: Fondo de cuenca (3400-3550 m.s.n.m.); Sectores intermedios (3550-380o m.s.n.m.) y Quebradas de altura (3800-4600 m.s.n.m.).

\section{Introducción}

Las redes de riego están compuestas por un amplio conjunto de dispositivos hidráulicos que van desde simples canales excavados a acueductos de mayor complejidad arquitectónica. La arqueología hidráulica en distintas partes del mundo ha demostrado que las redes de riego pueden ser altamente variables en espacio, tiempo y contexto social en que se generan (Farrington, 1980; Ortloff, 2009; Purdue y Berger, 2015; Quesada, 2011; Santoro et al., 1998). De este modo, atendiendo a la variabilidad mencionada, identificar las partes de la red y establecer la vinculación funcional entre estas permite configurar el diseño de la red y se vuelve clave para lograr entender los espacios hidráulicos y cómo estos funcionaban y eran administrados (Kirchner y Navarro, 1996). Además, el estudio de los espacios hidráulicos del pasado en zonas áridas permite reconstruir los paisajes agrarios, los cuales constituyen una categoría sintética de la producción campesina tanto en sus aspectos técnicos como políticos (Quesada, 2011).

En la Puna argentina son muchos los sitios arqueológicos donde el estudio del espacio hidráulico ha sido importante para entender los paisajes agrarios, por ejemplo Laguna Blanca, Tebenquiche Chico, Antofalla, Casabindo, Aguas Caliente de Rachaite, Bajo del Coypar, Santa Ana de Abralaite, entre otros (Albeck, 1993; Albeck y Scattolin, 1984; Díaz, 2009; Krapovickas, 1984; Krapovickas, Castro y Meroni, 1980; Olivera, 1992; Ottonello de García Reinoso, 1973; Quesada, 2001, 2007, 2011; Raffino, 1972). Esto demuestra que, desde tiempos prehispánicos, la agricultura de riego no sólo era de gran importancia en la economía puneña, sino que presentó una cierta variabilidad, tanto en la configuración de los diseños de las redes, como en las escalas espaciales y temporales de los procesos de trabajos agrícolas que involucraba su construcción, uso y gestión.

Específicamente en Antofagasta de la Sierra, localizada en la Puna catamarqueña, existen diversas evidencias arqueológicas que indican la importancia de las prácticas de cultivo en las sociedades agropastoriles, las cuales estuvieron sujetas a diferentes roles y dinámicas a lo largo de los últimos 3000 años (Babot, 2006; Escola et al., 2013; Gasparotti, 2015; Grant, 2014; Killian Galván y Salminci, 2014; Oliszewski y Olivera, 2009; Olivera y Vigliani, 2000-2002). Hasta el momento, la mayoría de las evidencias de las tecnologías de riego prehispánicas provienen de los sitios Bajo del Coypar I y II, ubicados en la planicie aluvial del río Punilla y Los Colorados (sector fondo de cuenca ${ }^{1}$ ). Allí se registraron diversas estructuras agrícolas (melgas, parcelas delimitadas por bordos de sedimentos, depósitos de almacenaje, etc.) e hídráulicas (canales primarios y secundarios, drenajes de desagote, etc.) vinculadas al cultivo de especies comestibles y/o para el desarrollo de pasturas para el ganado (Olivera y Vigliani, 2000-2002; Salminci, 2012; Tchilinguirian y Olivera, 2011). Asimismo, en las quebradas de Las Pitas, Miriguaca y Mojones-Beltrán también se han identificado diversas estructuras agrícolas e hídráulicas, como campos de cultivos y canales de riego (Grana Cohen y Maidana, 2014; Tchilinguirian y Olivera, 2011).

En este marco, este trabajo se centra en el estudio de una red de riego prehispánica ubicada en el sector sur de la cuenca inferior del río Miriguaca (entre los $26^{\circ} 1^{\prime} 23^{\prime \prime}-25^{\circ}$ $59^{\prime} 58,6^{\prime \prime}$ S y $67^{\circ} 24^{\prime} 21,3^{\prime \prime}$ - 67 22' 49,6”O) (Figura 1). Esta fue identificada y descripta anteriormente por Tchilinguirian y Olivera (2011) en un trabajo a escala regional, donde se la presenta junto a otros diseños de redes de la región. Los autores denominan a esta red como Miriguaca Sur 1 (MS1) y la caracterizan en base a la presencia de 90 parcelas de campo de cultivo que se extienden a lo largo de la ladera oriental de la Sierra Punilla y por poseer canales con una longitud máxima de $12 \mathrm{~km}$, cuya bocatoma se ubicaría en el cauce del río Miriguaca. Sin embargo, las recientes prospecciones y análisis que hemos realizado en el año 2016, muestran un diseño distinto y de mayor complejidad que el reconocido previamente. Por este motivo, este trabajo tiene como 


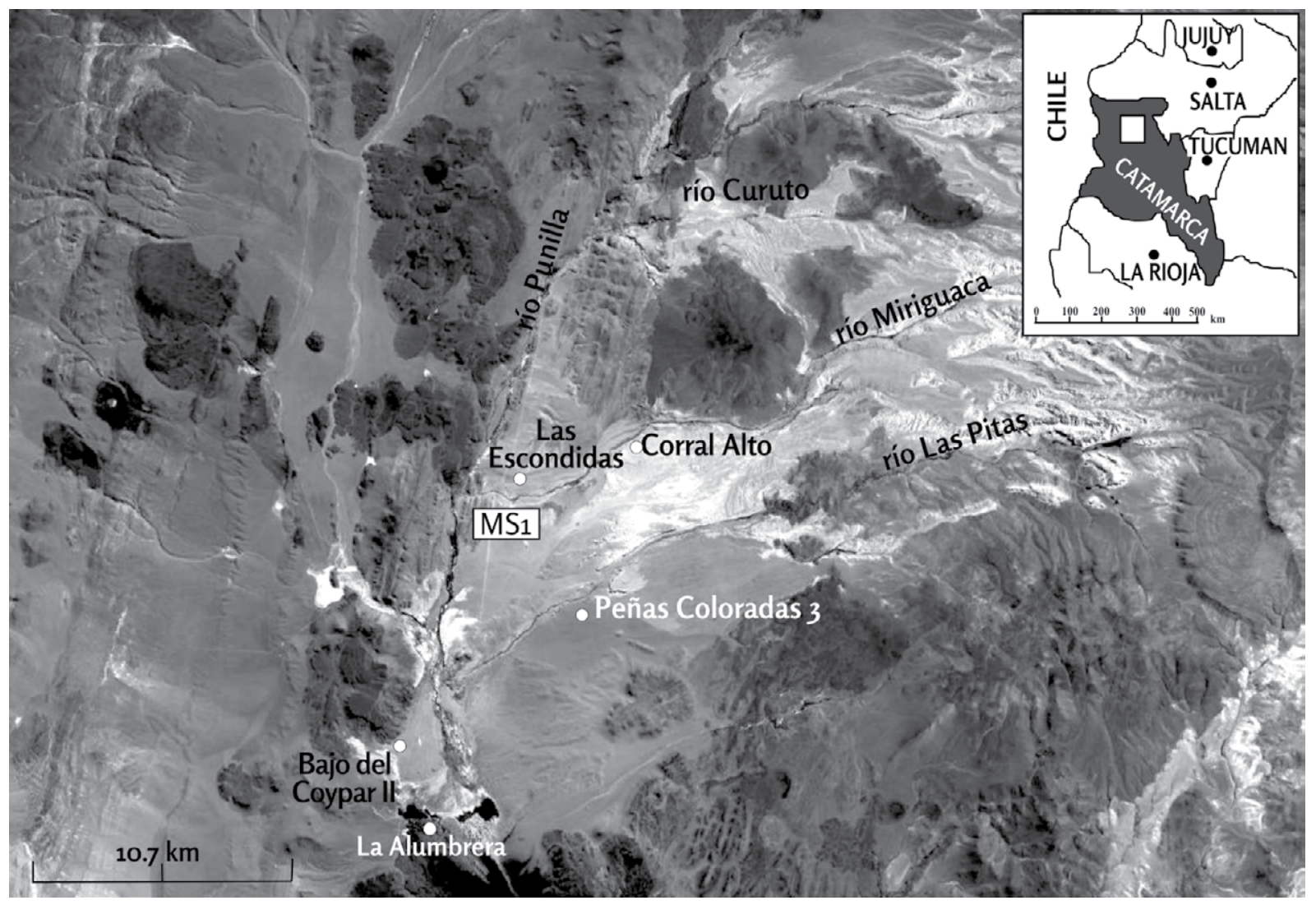

Figura 1. Ubicación geográfica de la red analizada río Miriguaca 1 (MS1) y de los sitios arqueológicos mencionados en el artículo.

objetivo presentar las evidencias halladas recientemente de esas antiguas tecnologías hidráulicas y, a partir de ellas, brindar una caracterización del diseño de red de riego MS1. El análisis de esta red de riego permite profundizar sobre las interpretaciones del funcionamiento y de los diseños hidráulicos de las redes conocidas hasta el momento para la Puna meridional.

\section{Metodologías}

El análisis de estas evidencias es dificultoso debido a su naturaleza, ya que algunos elementos constitutivos de las redes a veces son construidos con simples técnicas (como un despedre, bordos de sedimentos etc.), y en consecuencia suelen tener una pobre conservación y visibilidad en el terreno (Quesada, 2011). Por lo tanto, es recomendable trabajar, de manera complementaria y empleando diferentes escalas de observación (Quesada, 2007; Salminci, 2012). Nuestra aproximación involucró dos escalas. La primera consistió en un reconocimiento de la red de canales a través de imágenes satelitales de alta resolución, ya que algunos de los mismos tienen patrones claros sólo cuando la observación se la efectúa remotamente desde posiciones elevadas. Esta estrategia de observación permitió, además, detectar otros rasgos no vinculados a las redes de riego pero que o las impactaron o podrían ser confundidos con algún dispositivo hidráulico. Por ejemplo, las rutas vehiculares pueden diferenciarse en las imágenes de sensores remotos ya por su doble linealidad y porque no mantienen pendiente negativa. De este modo, para este primer abordaje utilizamos las imágenes procesadas brindadas por el programa Google Earth Pro ${ }^{\circ}$ v 7.3.1, ya que ofrece imágenes satelitales de distintas resoluciones provenientes de diferentes satélites (Landsat 4, 5, 7 y 8) y tomadas en distintos años (p. ej. 2002-2017 para nuestra área de estudio). Por lo tanto, es posible observar y comparar un mismo lugar con diferentes imágenes tomadas 
en distintos momentos, permitiendo así reconocer más rasgos del terreno. Otra ventaja es que se pueden digitalizar directamente en el software todas las estructuras visibles identificadas en las diferentes imágenes a través de las herramientas de puntos, líneas y polígonos con datos georeferenciados.

Asimismo, para establecer las conexiones entre los distintos dispositivos hídráulicos se buscó, a partir de la línea de rigidez indicada por la posición del canal principal (Barceló, 1996), observar las posibilidades ofrecidas por los desniveles para la conducción del agua, ya que en sistemas de riego por gravedad el agua siempre requiere pendientes negativas para circular. Se trata de un método de reconstrucción del diseño de las redes de riego que ya habíamos aprovechado ventajosamente en una investigación anterior (Quesada, 2007). Para ello se generó un modelo digital del sistema de isolíneas (curvas de nivel con una equidistancia de $10 \mathrm{~m}$ ) procesando imágenes satelitales ASTER GDEM (resolución $15 \mathrm{~m}$ ). El trabajo a esta escala de observación permitió generar una primera aproximación exploratoria que definió un modelo preliminar de diseño de red de riego.

Sin embargo, esta aproximación necesita del control terrestre, lo que involucra una segunda escala de observación que se centra en la prospección pedestre y el relevamiento con instrumental de precisión como GPS y niveles ópticos (Kirchner y Navarro, 1996; Salminci, 2012). Para esto en un equipo portátil con acceso a GPS se cargaron diversos puntos generados de las digitalizaciones de las estructuras hidráulicas en Google Earth (puntos del camino). Estos puntos fueron corroborados y corregidos con exactitud en el terreno. Además, en el campo se relevaron y georreferenciaron nuevas estructuras no observadas en la etapa anterior. Las prospecciones pedestres y los relevamientos arqueológicos son un paso importante no sólo para ajustar el registro de la configuración espacial de las redes hídricas prehispánicas, sino también para reconocer variantes tecnológicas de los dispositivos hidráulicos y recuperar material arqueológico superficial asociado a los dispositivos hidráulicos que permitan brindar cronologías relativas (Albeck, 1993). En este contexto, en algunas de las estructuras hidráulicas reconocidas en el campo también se realizaron sondeos para registrar las tecnologías de construcción. Finalmente, se realizaron planialtimetrías con nivel óptico con el objeto de tener un mayor detalle de las dimensiones de algunos componentes hidráulicos de la red de riego, aplicando el método de taquimetría. Las descripciones de los dispositivos hidráulicos siguieron las terminologías propuestas por Albeck $(1993)$ y Quesada $(2001,2007)$ para los canales y por Lanzelotti (2011) para la represa. Los datos generados en ambas escalas de observación se combinaron y las imágenes fueron procesadas digitalmente y mejoradas con el software Adobe Photoshop CC 2017 y Corel Draw X7 para su mejor visualización.

El material cerámico superficial recolectado fue abordado a través de un análisis macroscópico y sub-macroscópico con lupa binocular (4x a 40x) (Cremonte, 1988; Orton, Tyre y Vince, 1997; Rye, 1988; Sinopoli, 1991; Zagorodny, 2000). Se relevaron diversos atributos que refieren a la manufactura, como aquellos relacionados con el preparado de la arcilla, el levantado de la pieza, los tratamientos y acabados superficiales, la cocción y finalmente, la existencia de marcas o trazas relacionadas con el uso y el descarte o depositación (Skibo, 1992).

\section{Resultados}

Todos los canales registrados se ubican en el piedemonte de la cuenca inferior del río Miriguaca y se caracterizan por ser simplemente surcos cavados en el suelo sin mayores acondicionamientos técnicos. Es por ello que presentan una visibilidad baja, distinguibles en el terreno por leves depresiones longitudinales, cambios de color en el sedimento y/o lineamientos de rocas que habrían conformado los bordos de los canales (Figura 2, Figura 3A, B, C). En los sectores más cercanos al cauce se registran 

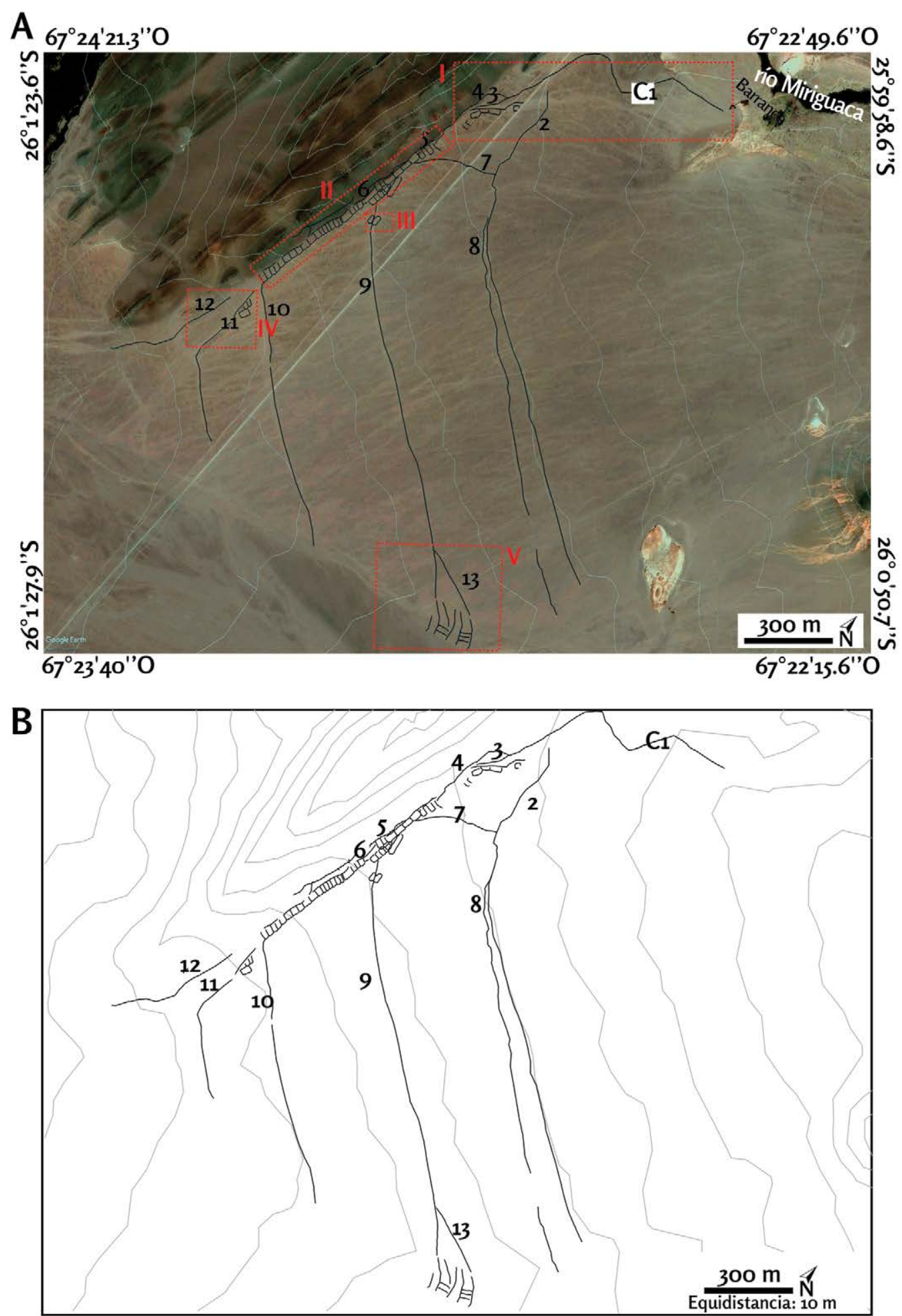

Figura 2. A) disposición espacial de la red MS1 y todos los dispositivos hídráulicos reconocidos en la imagen satelital de Google Earth pro 7.3.1. Los sectores de la red están señalados con números romanos y los canales con números arábigos. $C_{1}$ es el canal principal identificado para la red; B) plano altimétrico de la red MS1.

varios deslizamientos y barrancos que impiden seguir el reconocimiento del canal principal para identificar la bocatoma inicial de la red (Figura 2). Actualmente el curso del río se encuentra aproximadamente $20 \mathrm{~m}$ por debajo a la ubicación 

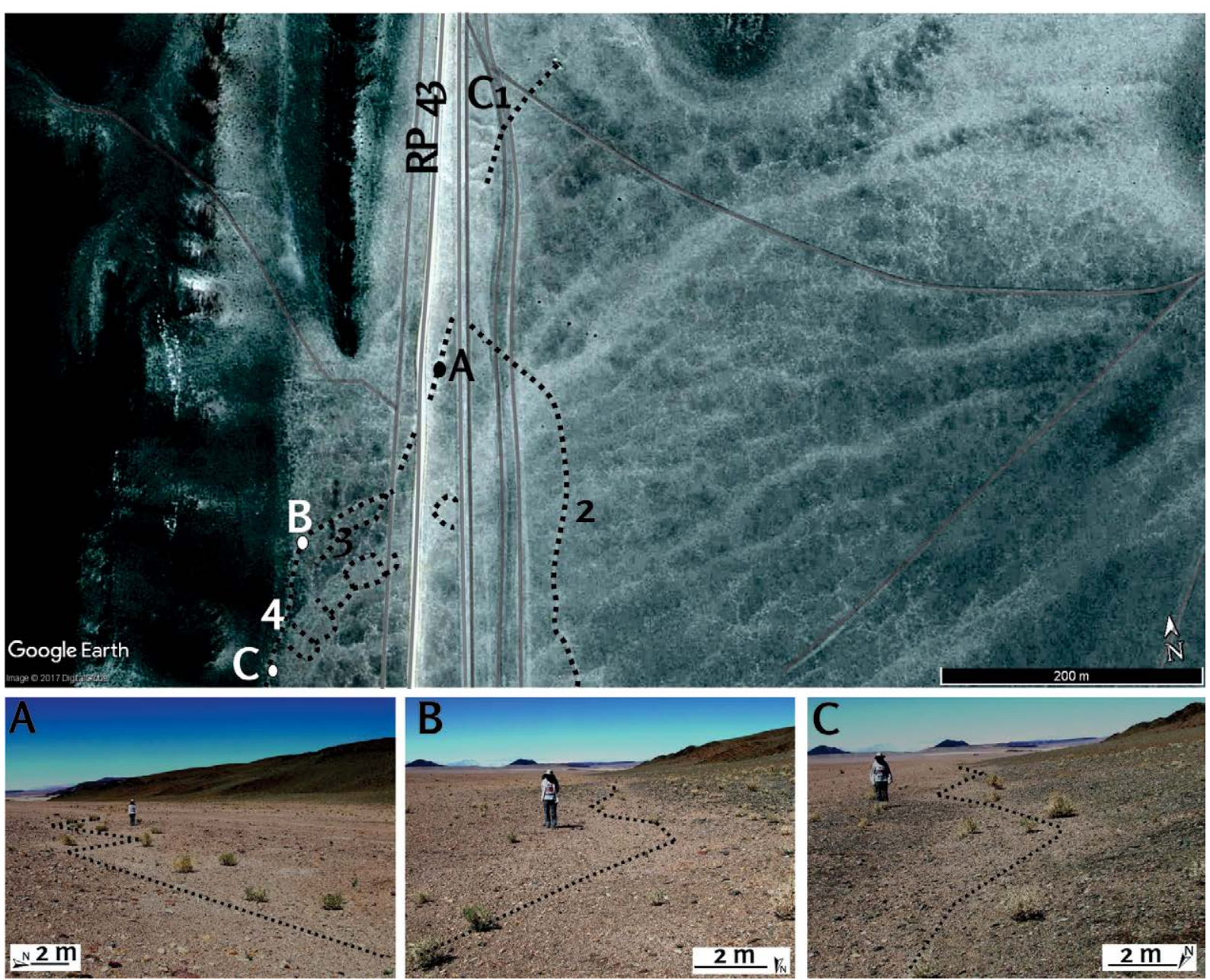

Figura 3. Imagen satelital del sector I. Las líneas negras punteadas señalan los surcos de los canales y campos de cultivo reconocidos. Las líneas grises enteras señalan caminos y rutas que impactan sobre la red. A) Canal [C1], la línea negra marca la dirección del canal; B y C) Canal [4], la línea negra marca la dirección del canal.

de la red de riego. Posiblemente la incisión que formó el cañadón por donde discurre hoy se habría producido con posterioridad a los 1400 años AP (Grana, Tchilinguirian, Olivera, Laprida y Maidana, 2016; Tchiliguirian, 2009). Por su parte, la ruta provincial 43 (RP43) es uno de los principales factores de destrucción ya que atraviesa varios canales y campos de cultivos alterando su conservación y visibilidad (Figura 2). Para brindar una descripción adecuada se dividió la red en cinco sectores en relación a un mero orden espacial y no de funcionalidad ya que son sectores relacionados entre sí.

El sector I incluye el canal principal [C1], el cual tiene una orientación noroeste-sureste y una pendiente que indica que tomaba agua del río Miriguaca. Este canal direcciona el agua hacia los faldeos del afloramiento de rocas del Ordovícico, visible en tono oscuro en el ángulo superior izquierdo de la figura 2, donde luego se estableció la presencia de canales secundarios, parcelas de cultivo despedradas y una represa (Figura 2).

En las imágenes satelitales se observa que el canal principal tuvo al menos tres modificaciones en su recorrido en relación a la alimentación de la red (Figura 3). El primer cambio se registra cerca de la ruta RP43 con la bifurcación de dos nuevos canales secundarios, uno con dirección al noroeste [2] que corre paralelo a la ruta y otros (canal [3] y [4]) con dirección al este, hacia los faldeos (Figuras 2-3). El canal [3] tiene una 
vinculación funcional con la red por medio de canales terciarios que riegan una mayor cantidad de parcelas de cultivos al noroeste, estableciendo así el límite máximo de esta red hacia el norte (Figura 3A). Por su parte, no se descarta que hayan existido otros canales terciarios que podrían haber salido del canal [2], ya que en el medio de la ruta se registran algunas parcelas de cultivo. Sin embargo, esta zona está muy erosionada y ha sido difícil distinguir canales en el terreno (Figura 3A, B, C). El canal [4] corre en paralelo al faldeo (Figura 3) y desemboca al noreste de la represa, por lo que cumple con la función de abastecer esta estructura hidráulica (Figura 4A).

El canal secundario [2] corre hacia el este aproximadamente por $418 \mathrm{~m}$ y en paralelo a la ruta RP43, donde posteriormente surge un canal terciario [7] que se vincula con los campos inferiores del sector II. Luego, el canal [2] cambia de sentido dirigiéndose hacia el este y se bifurca en otro canal [8], donde ambos corren en el mismo sentido sin volver a contactarse. Es necesario señalar que aún no han podido ser identificadas las parcelas que eran abastecidas de riego mediante estos canales (Figura 2).

En el sector II se registra la presencia de un bordo de tierra en forma semicírculo y con dirección perpendicular al faldón y al canal [4], con $60 \mathrm{~cm}$ de altura promedio con respecto a la superficie actual (Figura 4B, Figura 5). Este semicírculo delimita al vaso $^{2}$ y disminuye en altura al sureste dando se origina un escape del agua, que habría funcionado como el vertedero para controlar el nivel de agua de la represa (Figura 5). Al suroeste se ubica el ducto de salida que alimenta al canal de riego [5] (Figura 4A, Figura 5). El análisis espacial y arquitectónico muestra que esta estructura habría tenido una funcionalidad de represa, ya que captura el agua del canal [4] al norte y desagota al sur en el canal [5] (Figura 5 y 6).

El vaso de la represa se ubica en un sector deprimido del terreno y mide 38 x 29 m, el cual habría tenido una capacidad mínima de almacenar $370 \mathrm{~m}^{3} \mathrm{de}$ agua (Figura 5). El ducto de salida de la compuerta fue reconocido en superficie por medio de 6 lajas grandes clavadas verticalmente en el terreno (Figura 4B, Figura 6A). El sondeo realizado en este sector permitió corroborar la estructura del ducto de salida. Esta estaba entubada por varias lajas planas que componían tanto las paredes, como el piso y el techo de la estructura (Figura 6B, D y E). In situ se conservan varias lajas largas clavadas juntas y tres lajas grandes apoyadas en el suelo (Figura 6B, C, F y E). En la superficie aparecen varias lajas semejantes a las anteriores dispersas en el terreno que podrían haber sido parte de la estructura ${ }^{3}$ (p. ej. techo del canal de salida) (Figura 4B). El marco de salida tiene una forma trapezoidal $(36-29-29-32,5 \mathrm{~cm})$ y la base está a una profundidad de 50 $\mathrm{cm}$ en relación a la superficie exterior del techo (Figura 6C). El extremo final del ducto de salida de la represa está construido como una pequeña cámara de aquietamiento. Las lajas que revisten el fondo del canal tienen, en esta sección, pendiente positiva y la última fue colocada en un pronunciado ángulo de $45^{\circ}$ (Figura $6 \mathrm{~F}$ ).

Un depósito de gravas pequeñas y redondeadas hallado en el fondo de esta cámara se distingue del sedimento que rellena el ducto, el cual está conformado principalmente por arena gruesa-medias. Esto podría estar indicando una disminución de la velocidad del agua y, por lo tanto, de su capacidad de transporte. La incorporación de este dispositivo al ducto de salida habría tenido la finalidad de controlar la velocidad del agua a la salida de la represa, logrando la entrega al canal [5] de un flujo aquietado y de baja capacidad erosiva.

El canal de riego de egreso de la represa [5] tiene un recorrido de $1 \mathrm{~km}$ recto recorriendo el pie del faldeo. En su recorrido riega varias parcelas de cultivo de forma rectangular con distintos tamaños (Figura $4 \mathrm{~B}$ y C) y, por medio de canales secundarios como el canal [6], que corre a una altura inferior, riega otros campos de cultivo más alejados (Figura 7).
2. El vaso corresponde a la parte de la estructura que contiene el agua embalsada (Lanzelotti, 2012).
3. Al parecer la estructura del ducto de salida de la represa fue objeto de una excavación anterior que además de retirar algunas lajas del techo destruyó la sección del bordo que las cubría. Probablemente los excavadores creyeron que se trataba de una cámara funeraria subterránea revestida con lajas, que son parte de una modalidad de entierro común en la región. 

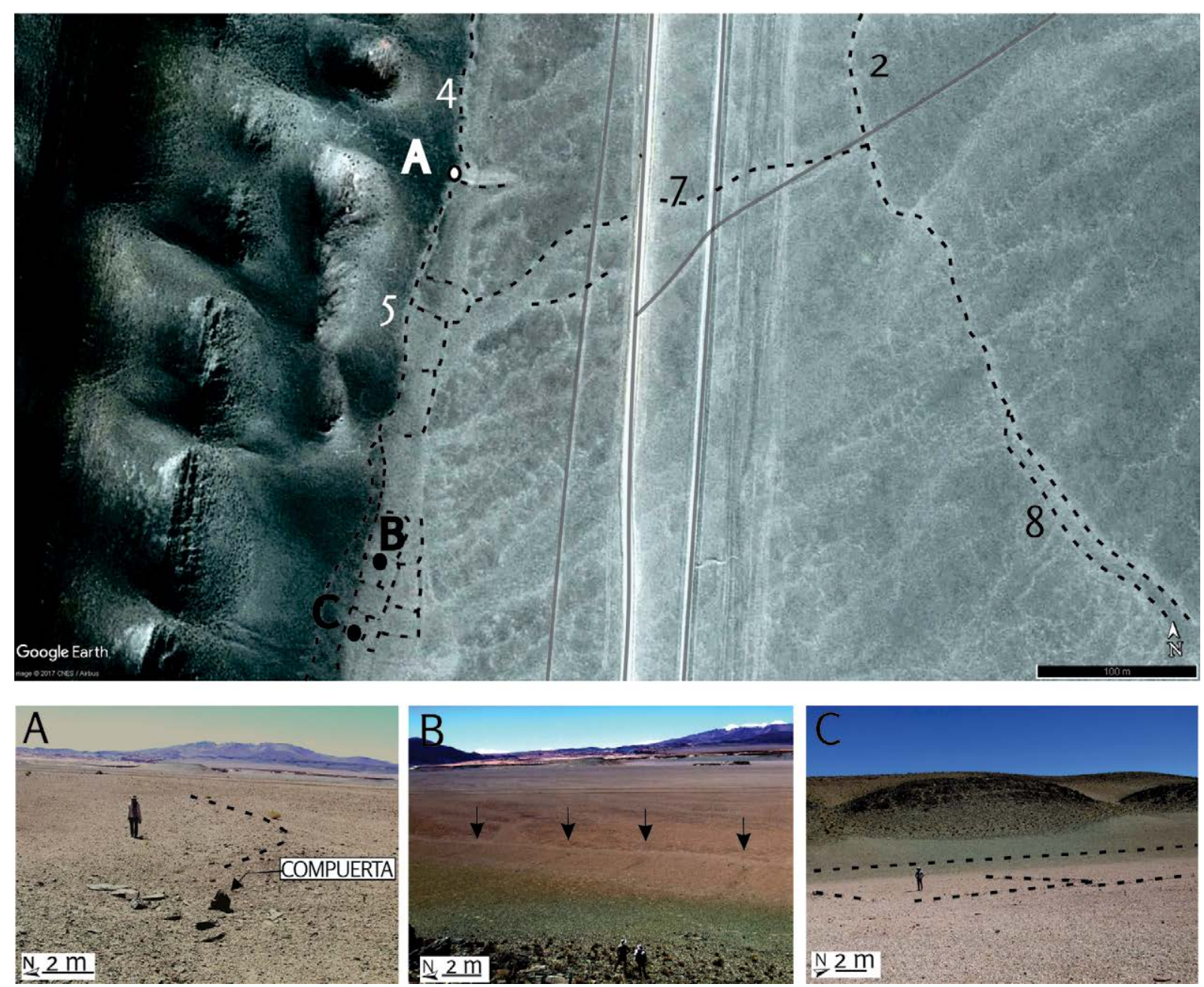

Figura 4. Imagen satelital del Sector II. Las líneas negras punteadas señalan los surcos de los canales y parcelas de cultivo reconocidas. Las líneas grises enteras señalan caminos y rutas que impactan sobre la red. A) imagen de las lajas superficiales que muestran la compuerta, la línea punteada marca el bordo de tierra que forma parte de la represa; B) parcelas de cultivo con bordos; las flechas señalan el paso del canal [6]; C) parcelas de cultivo con bordo y canal [5] delineados con líneas punteadas.

Por otro lado, las parcelas de cultivo ubicadas en la parte inferior del sector II podrían haber sido regados por el canal terciario [7], que nace del canal [2], y por los canales secundarios derivados del canal [5] (Figura 4). Este sector presenta la mayor cantidad de parcelas de cultivo, las cuales se reconocen por estar despedradas generando alineamientos de piedras, que posiblemente en el pasado conformaron bordos pero que actualmente están erosionados (Figura 7A, Figura 8). En este sector, además, es donde la visibilidad de los campos es mayor (Figura 2).En total, se reconocen como mínimo 49 parcelas de cultivos de diversos tamaños, delimitados por bordos creados por el despedre del terreno, que abarcan ca. 2,81 ha (Figura 7). La parcela de mayor tamaño mide aproximadamente 60 x $17 \mathrm{~m}$ y la más pequeña $19 \times 8 \mathrm{~m}$. En este sector de parcelas inferiores derivan a partir del canal [6] otros cuatro canales de orden inferior. Los canales [10] y [9], con una disposición recta, se direccionan hacia el este donde se encuentra el sector V (Figura 2, Figura 8A). Luego, los canales [11] y [12] muestran un direccionamiento hacia el sur. Estos canales conforman el sector IV, donde se pudo registrar que, al inicio del canal [11], se habría regado un conjunto pequeño de parcelas de cultivo.

Por último, el sector $\mathrm{V}$, aún no ha podido ser registrado en terreno y su descripción se basa sólo en el análisis de imágenes satelitales (Figura 2). Este sector está conformado 


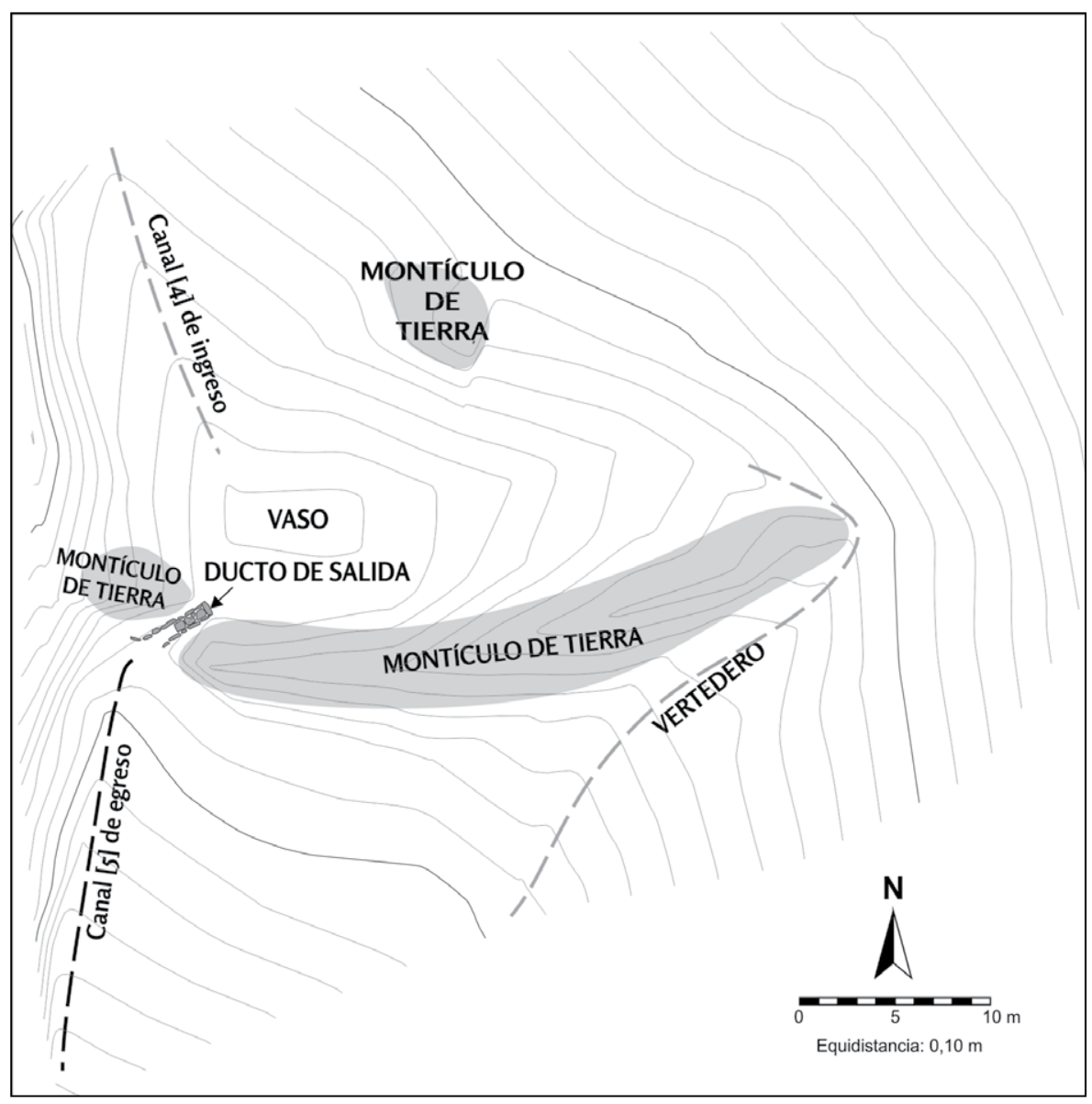

Figura 5. Plano altimétrico de la represa y los elementos que la componen.

por el canal [9], del cual se desprende el canal secundario [13] y luego una serie de canales terciarios que riegan una serie de parcelas de cultivo que se disponen en forma de abanico.

Cabe destacar que se registra una serie de recintos que, en relación a su disposición espacial, algunos presentan vinculación con la red de riego y otros no. En una de abra del faldeo se observa un puesto histórico asociado a un corral que no parece tener vinculación con la red de riego. En cambio, cercano a los canales [5] y [6] se encuentran dos estructuras pequeñas, de planta rectangular (E1 y E2) (Figura 8B) que podrían tratarse de refugios u otro tipo de albergues no muy elaborados vinculados al trabajo de los campos agrícolas y operación de los dispositivos de riego. En otras redes de riego de Miriguaca, como en Tebenquiche Chico y Antofalla, estas últimas localidades cercanas a Antofagasta de la Sierra $(c a .80 \mathrm{~km})$, se han registrado estructuras pequeñas subcirculares que fueron incorporadas como componentes de las redes de riego. Se asume que si bien no son estructuras hídráulicas estos refugios están vinculados a la gestión del riego y proporcionaron refugio durante las tareas agrícolas (Quesada, 2007). Quesada (2007) las caracteriza como estructuras con una construcción poco elaborada, suelen tener material en superficie de elementos de actividad agrícola (p. ej. fragmentos de palas) y localizarse en lugares lejanos a la bocatoma de la red. Si bien las estructuras halladas en MS1 tienen plantas rectangulares, sus tamaños son reducidos y sus localizaciones lejanas a la bocatoma de la red, nos permitirían inferir que también se tratarían de refugios de riego. 

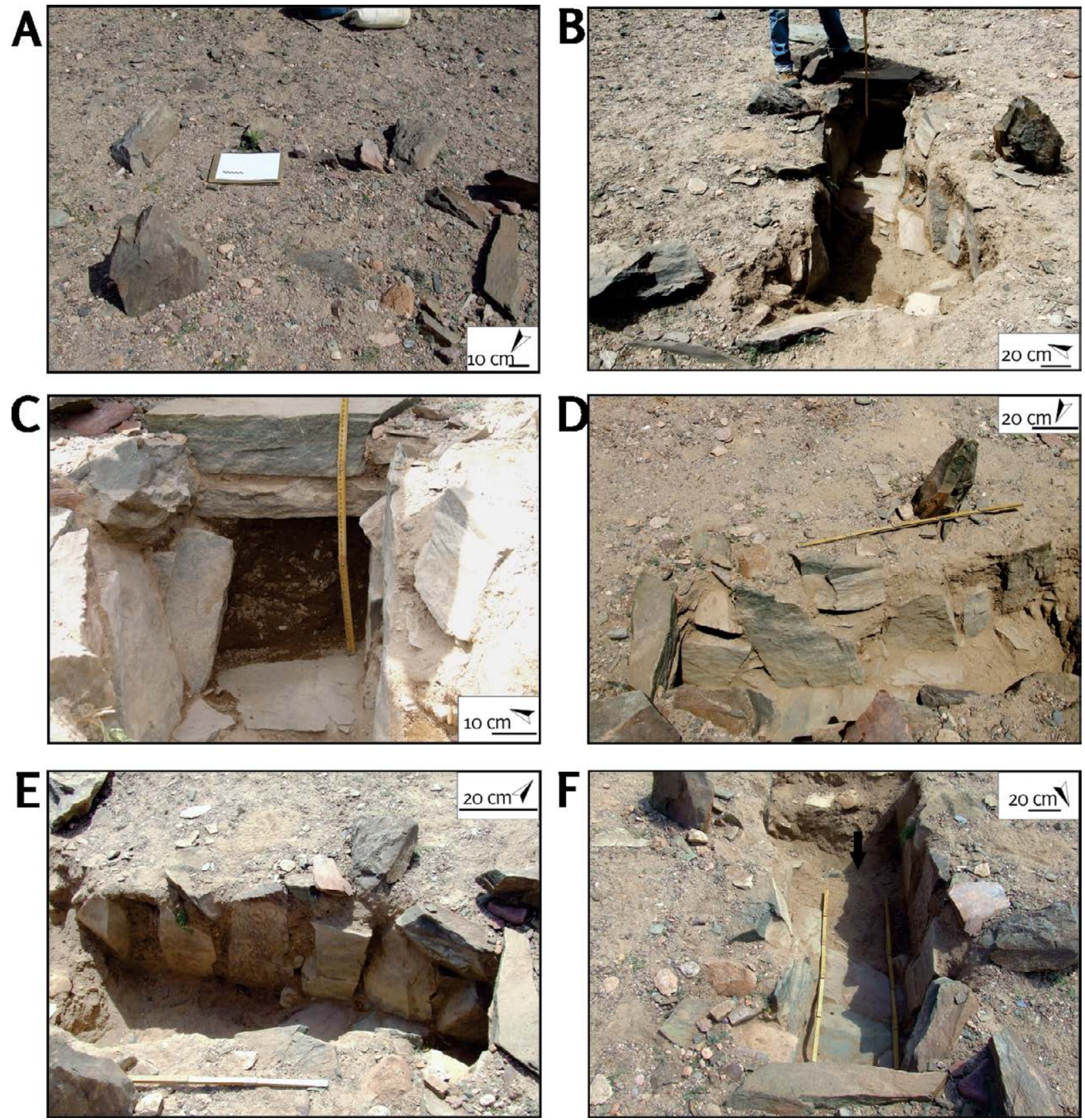

Figura 6. Fotografías del ducto de salida de la represa. A) inicio de excavación del sondeo del ducto de salida; B) fin de excavación del sondeo donde se expone todo el ducto de salida; $C$ ) detalle del marco del ducto de salida; $D$ y $E$ ) detalle de las paredes laterales del ducto de salida; $F$ ) detalle del piso del ducto de salida con dirección al canal de egreso [5].

\section{Material en superficie}

La presencia de material en superficie es muy escasa. Se recolectaron 31 fragmentos cerámicos de los cuales 23 están decorados y ocho no lo están, hallados en un mismo sector. Sin embargo, a simple vista se puede proponer que todos los fragmentos pertenecieron a la misma pieza cerámica ya que presentan una gran similitud en sus pastas. En algunos fragmentos en los que no se observa una decoración clara se pudieron distinguir vestigios de pintura que los asemejan a aquellos fragmentos que aún presentan decoración, a través del uso de lupa binocular. El conjunto se compone de tres fragmentos de borde, dos de los cuales pudieron ser remontados, y dos fragmentos que posiblemente correspondan a remaches de asas. El resto del conjunto $(n=26)$ no 

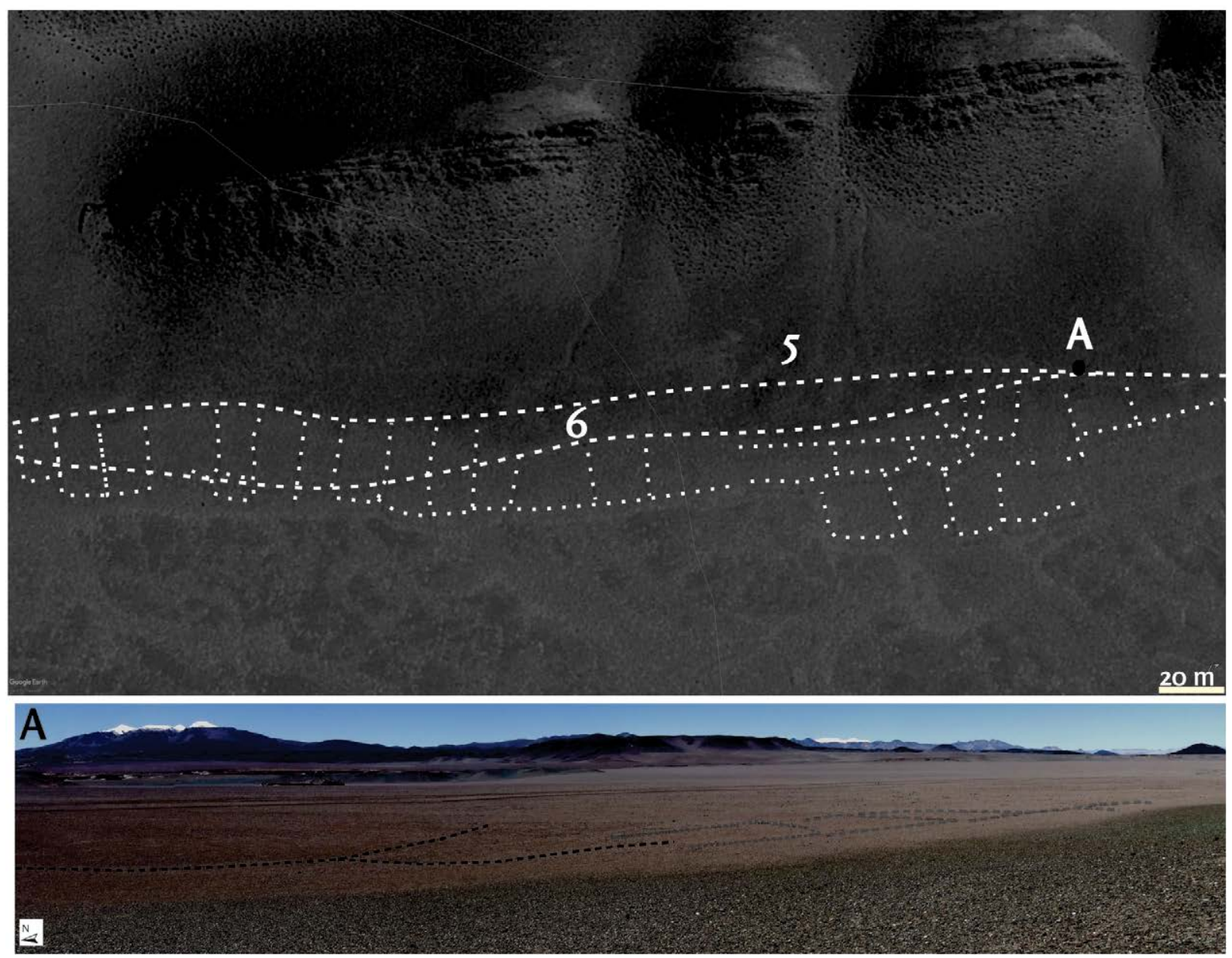

Figura 7. Sector II: disposición de las parcelas de cultivo y los canales [5] y [6], destacados con línea punteada. A) imagen de las parcelas de cultivos vistas desde el faldeo.

puede asignarse a una porción específica de una pieza por sus características, aunque posiblemente haya formado parte del cuerpo.

En cuanto a las técnicas de levantado de la pieza, no fue posible identificar ninguna traza o marca que haga referencia a esta etapa de la manufactura. Luego, a través del uso de lupa binocular se observaron las características de la pasta. Esta presenta una compactación alta, con una densidad de inclusiones que visualmente podría estimarse entre un 15 a 20\%. Para abordar las características de la forma de dicha pieza se tomaron en cuenta los bordes. Éstos presentan una sección del cuello, que se dispone de forma recta, y el diámetro interno alcanza los $16 \mathrm{~cm}$. El cuello es rematado por un labio evertido (labio convexo) que presenta un espesor promedio de 3,2 $\mathrm{mm}$. A partir de los bordes, se pudo estimar el diámetro de la boca en alrededor de $20 \mathrm{~cm}$. Finalmente, el espesor de las paredes fue estimado en $6,1 \mathrm{~mm}$ aproximadamente (Figura 9A).

Respecto a los tratamientos y/o decoración de la pieza, se puede afirmar que ésta fue alisada cuidadosamente en la superficie externa, mientras que en la interna se observan los rastros dejados por el instrumento utilizado. Posteriormente, la pieza fue decorada, aplicando en primer lugar un baño o engobe de color rojo en el exterior que no llegó a cubrir el labio de la vasija. En segundo lugar, las superficies externas fueron decoradas con motivos realizados en color negro, los cuales pueden asociarse visualmente a aquellos identificados para el estilo Belén (Figura 9A), como los motivos decorativos registrados en el valle de Hualfin (Wynveldt, 2009) o en La Alumbrera (Pérez, 2013) (Figura 9). Por 

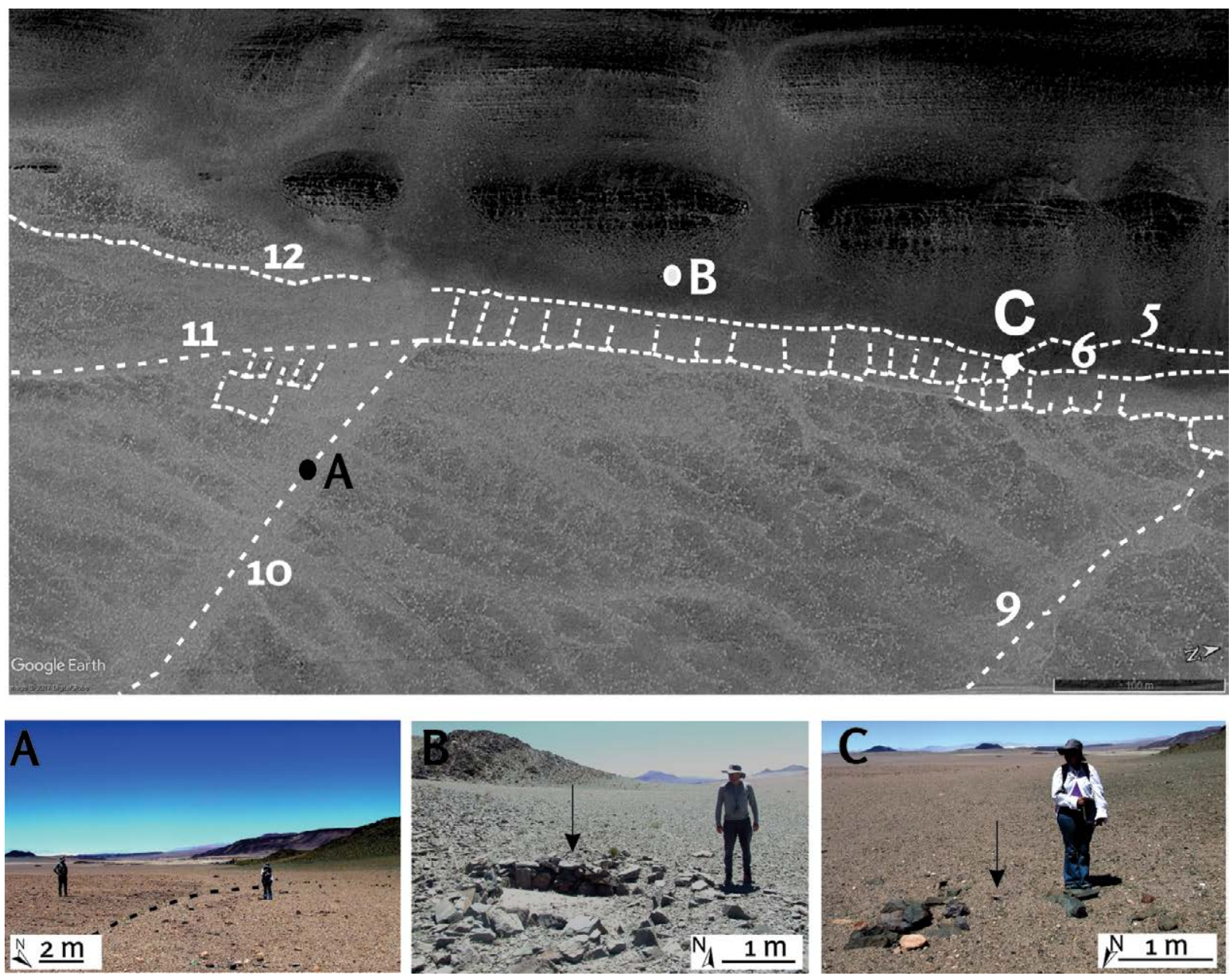

Figura 8. Imagen satelital de los Sectores III y IV. Las líneas negras punteadas señalan los surcos de los canales y parcelas de cultivo reconocidos. A) imagen del canal [10]; B) refugio relacionado espacialmente con la red de riego; C) detalle del canal de ingreso del agua de riego a una parcela de cultivo.

su parte, en el interior de la pieza sólo se observan manchas o salpicaduras de pintura negra. Finalmente, la pieza habría sido cocida en una atmósfera oxidante, con bastante control de la misma, ya que no se observan manchas de cocción.

\section{Discusión}

\section{Caracterización del diseño de red}

La observación a distintas escalas en este sector de la cuenca inferior de Miriguaca permite modificar y ampliar la caracterización del diseño de la red de riego MS1 que se conocía hasta el momento (Tchilinguirian y Olivera, 2011). En este sentido, se reconoció una mayor cantidad no solo de campos de cultivo sino también de canales, e incluso modificaciones de los mismos que complejizan los aspectos funcionales y sociales de la tecnología de irrigación de esta red de riego.

En base al análisis del diseño de la red se puede establecer que ésta presenta un patrón centrífugo, ya que la conducción tiende a alejar el agua del acuífero. Esto supone que el límite del crecimiento no es fijado por el límite físico del mismo acuífero, como sucede en las redes de riego centrípetas donde la pendiente que moviliza el agua es nula 

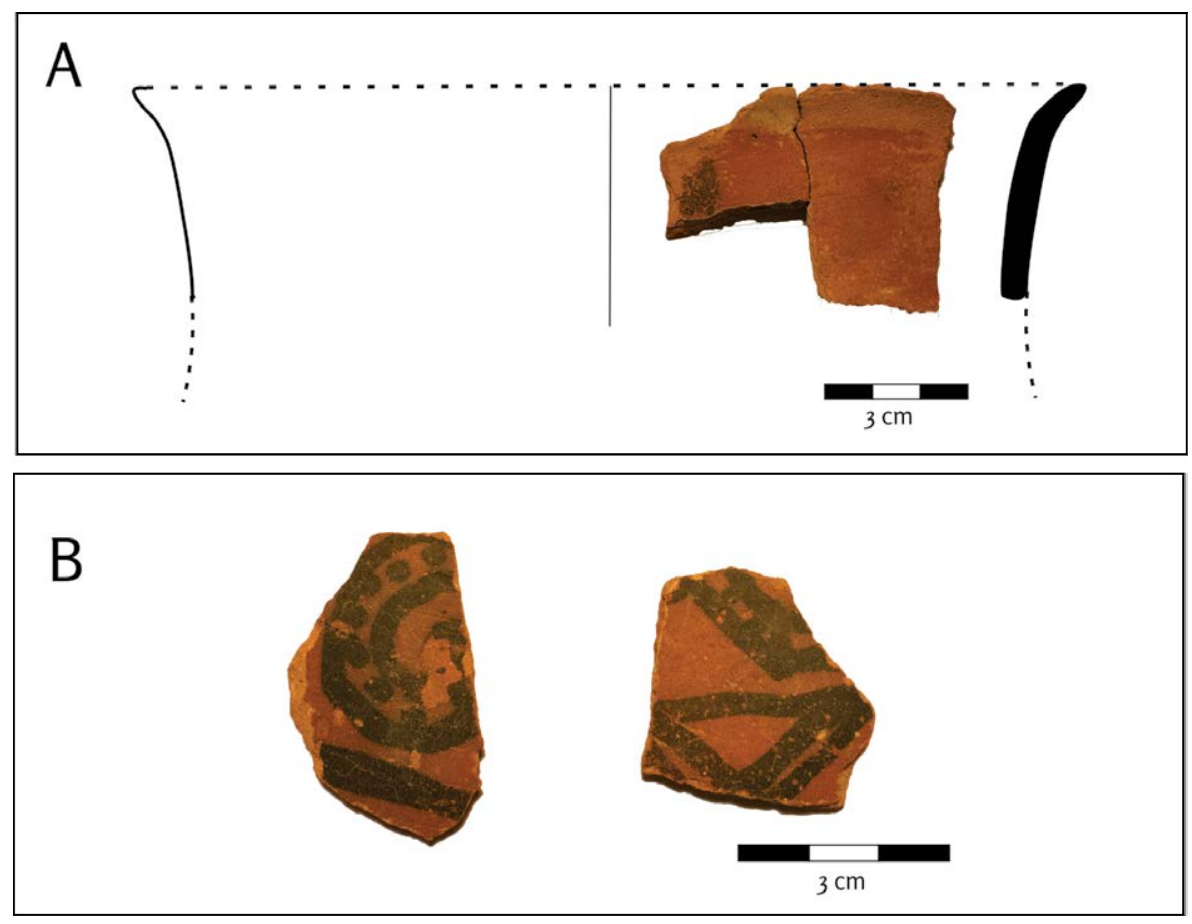

Figura 9. A) reconstrucción de un sector de la vasija; B) decoración de los tiestos analizados.

(Quesada, 2007). Más bien, el límite para la expansión de la red de riego MS1 es técnico, pues depende de la capacidad de las tecnologías involucradas para conducir el agua a mayores distancias. Principalmente, una de las características peculiares de la red de riego MS1 es la presencia de largas conducciones para abastecer de agua a sectores de parcelas relativamente pequeños. Cabe destacar que la tecnología de canales empleada es una de las más simple (surcos excavados) y con altas perdidas de infiltración en suelos arenosos puneños (Salminci, 2012). Por lo que las pérdidas por infiltración serían las principales limitantes a la expansión de esta red de riego.

Otra característica de la red de riego MS1 es su centralización técnica, ya que una gran cantidad de componentes parecen resultar funcionalmente dependientes de una bocatoma localizada en el río Miriguaca y de un sólo canal principal, que una vez establecidos condicionaron las sucesivas ampliaciones. El canal principal de la red habría sido modificado al menos tres veces, lo que puede interpretarse como cambios en el manejo del riego, principalmente en relación a la magnitud del espacio regado. Si bien aún no podemos establecer una cronología para estos cambios, es posible advertir que, en algún momento, el riego fue alimentado inicialmente por el canal [3], adicionando una mayor extensión de campos de cultivo al norte, marcando la línea de rigidez de la red. En otro momento, el canal C1 se bifurca y da nacimiento al canal [4] para generar un canal de ingreso a la represa. En otro momento, los agricultores decidieron iniciar el riego de la red más al sur con el canal [7] abarcando sólo los campos inferiores sin regar los superiores y sin la utilización de la represa para el riego. Aún no se puede establecer si estos cambios en el riego fueron complementarios entre sí. Una posibilidad es que se haya efectuado un uso sincrónico para regar una mayor extensión de campos o intensificación en algún sector puntual de la red de riego. Otra alternativa es que estos cambios se hayan dado en momentos distintos (diacrónicos) y representen distintas adhesión de sectores de riego o usos sectorizados a lo largo del tiempo. Independientemente al momento del cambio, estas modificaciones representan distintas gestiones del espacio agrícola dentro del diseño de la red de riego, que claramente implican intencionalidades puntuales de los campesinos. 
En relación al crecimiento de la red, si bien pareciera que los sectores I y II habrían tenido una expansión ordenada y pautada, basándonos principalmente en la limitación de parcelas continuas y semejantes entre sí, esto no habría sido en toda la red. Por ejemplo, la presencia de canales que cortan los campos (p. ej. canal [6]) y la existencia de canales dirigidos a sectores particulares (p. ej. canales [7], [10] y [11]), indicaría que no siempre fue una expansión planificada de antemano y se necesitaron estrategias puntuales para responder a necesidades de riego particulares.

Por otro lado, el registro de pequeñas elevaciones compuestas de sedimentos y rocas indica el uso de bordos para la delimitación de las parcelas de cultivos. El empleo de esta tecnología permite la creación de microclimas (disminución de vientos, evapotranspiración y heladas) y la minimización de la salinización del suelo que favorece al cultivo (Salminci, Tchilinguirian y Lane, 2014; Tchilinguirian y Olivera, 2011). También su presencia indica la forma del riego empleada por los campesinos que fue por medio de inundación de las parcelas (Salminci, 2012).

Es necesario remarcar que una novedosa técnica de riego prehispánico para la región es el empleo de la represa, ya que no son abundantes en el Noroeste Argentino (Albeck, 1993, 2011; Lanzelotti, 2012; Scattolin, 2007). En la Puna meridional solo se ha registrado su uso en las redes de riego domésticas actuales en las comunidades de Antofalla (red de riego 42, Quesada, 2007) y de Antofagasta de la Sierra (García, Rolandi, López y Valeri, 2002). Estas represas están construidas con materiales modernos, como el cemento, para evitar las filtraciones y dar mayor estabilidad. En Antofagasta de la Sierra su uso tuvo escasa duración debido a rupturas en la estructura (García et al., 2002). En cambio, en Antofalla sigue siendo utilizada (Quesada, 2007). A nivel arqueológico no se había registrado el uso de estanques en Antofagasta de la Sierra, aunque, en forma de hipótesis Salminci (2012) propuso la posible presencia de este tipo de dispositivo en el sector II del sitio Bajo del Coypar I, como una tecnología de tipo "húmeda" (sensu Lane, 2009), o sea con el fin de acumular agua en zonas hidrológicas con escasez estacional de caudal. Lamentablemente, Salminci no alcanzó a documentarlas y por lo tanto desconocemos sus características técnicas y localizaciones en las redes de riego correspondientes.

Estas estructuras pueden ubicarse en diversos emplazamientos captando el agua de diversas fuentes ya sea por medio de la derivación de un curso de agua, interceptando las escorrentías de agua por lluvia o embalsando directamente el curso de un río (Lane, 2009; Lanzelotti, 2011). La función de las represas es almacenar agua y tener un mayor control sobre ella. Este control puede estar asociado a regular el nivel de agua para los momentos de mayor necesidad durante el ciclo vegetativo del cultivo (Lanzelotti, 2011), o cuando hay escasez estacional de caudal (Lane, 2009). También, la acumulación de agua permite controlar la extensión de riego, ya que a una mayor acumulación de agua, se incrementa el caudal para regar superficies más alejadas en relación a la represa. Estas funciones no son excluyentes y pueden alternarse y complementarse según los requisitos del momento para el riego.

Por otro lado, es importante considerar la localización de la represa dentro de la red de riego para inferir la intensión del control del agua por los campesinos. La represa en la red de riego MS1 se localiza en la sección media de la red. Por ejemplo, se ubica mínimo a $1,2 \mathrm{~km}$ del inicio del canal principal y, posteriormente, cuenta con la existencia de largos canales (p. ej. [5] y [6]) y canales distantes conducidos a sectores puntuales del paisaje (p. ej. [9] [10] [11] y [12]), que tienen un recorrido entre ca. 1,3$1,5 \mathrm{~km}$. Por consiguiente, es posible interpretar que al menos uno de los objetivos de la incorporación de la represa dentro del sistema de riego MS1 haya sido de la posibilidad de acumulación de agua para permitir una conducción de mayor distancia y de este modo recomponer los caudales en estos largos canales posteriores a la represa. Debido a que sin esta técnica estos canales llegarían bastante menguados al punto final de sus 
recorridos, considerando las altas pérdidas de infiltración que se generan en los canales de tierra abiertos y en estos ambientes desérticos.

Por otro lado, estudios actuales muestran que, independientementede la necesidad de contar con mayor cantidad de agua para riego o para tener una mayor extensión, el empleo de una represa en una red también implica un control sobre el tiempo del uso del agua (p. ej. turno de regado) (Martínez, 1987). Y esto a su vez podría repercutir en el planeamiento de otras actividades domésticas de estas sociedades agropastoriles. Por consiguiente, la represa dentro de un diseño de red permite postularla existencia de un control del tiempo.

En base a una recopilación de técnicas hidráulicas actuales y arqueológicas, Quesada, (2001) establece que las redes de riego son diseñadas en función de dos estrategias tecnológicas que pueden generan diseños particulares: maximización de la capacidad de transporte y minimización del riesgo, que no son excluyentes entre sí. Por ejemplo, un diseño confiable apunta a que las estructuras hidráulicas respondan al momento en que se desea regar, minimizando el riego. Por lo tanto, para ello se deben diseñar estructuras particulares que contrarresten la erosión y se adecuen al momento de riego. La segunda estrategia busca maximizar la capacidad de transporte generando así un diseño eficiente minimizando las posibilidades de pérdida de agua durante el manejo de la red (Quesada, 2007, 2011). Consideramos que el empleo de la represa dentro del diseño de riego de MS1 nos indicaría que se trata de una estrategia que apunta a generar un diseño de red confiable, ya que permite la acumulación de agua en un sector y aseguraría al agricultor el acceso al agua al momento de regar las parcelas. Además, algunos investigadores suelen considerar el empleo de represas como una tecnología que hace referencia a la "intensificación agrícola" (Scattolin, 2007). Sin embargo, en este caso antes que un mero incremento de la superficie agrícola, lo que se nota es un esfuerzo por alcanzar sectores puntuales pero restringidos bastante alejados del arroyo y entre sí. El significado de tal situación aún es desconocido.

\section{Cronología de la red de riego}

Establecer las cronologías de construcción y uso de las estructuras hídricas y de cultivo es una de las principales dificultades al trabajar con estas evidencias (Korstanje, Cuenya y Williams, 2010). Una de las estrategias propuestas es la estimación de cronologías relativas mediante asociación de cerámica con la estructura hídrica y la relación contextual con los sitios arqueológicos cercanos. Considerando que no hay evidencia de viviendas inmediatamente asociadas a la MS1, por lo que los campesinos que utilizaron esta red debieron residir en otro espacio. En base a este criterio, Tchilinguirian y Olivera (2011) sostienen que la red MS1 podría haber sido mayormente usada durante el Periodo Tardío (1100-500 años AP), aunque no descartan su posible uso durante el Formativo (2000-1600 años AP). Sus inferencias temporales se basan principalmente en la relación contextual de los sitios que se encuentran cercanos a la red MS1. Por ejemplo, el sitio Las Escondidas se ubica a $0,5 \mathrm{~km}$ al norte de la red y tiene dataciones radiocarbónicas que lo sitúan dentro del Formativo temprano (ca. 2000 - 1700 años AP) (Tchilinguirian y Olivera, 2011). Por otro lado, el sitio Corral Alto ubica cuenca arriba del río Miriguaca a $6 \mathrm{~km}$ de la red y ha sido adscripto a momentos del Tardío (Gasparotti 2015; Gasparotti y Escola, 2012; Tchilinguirian y Olivera, 2011). Pero recientes prospecciones arqueológicas en la cuenca baja del río Miriguaca han permitido identificar nuevos sitios adscriptos a momentos posteriores a ca. 1000 años AP, como Abra Toni y Pirca 18, localizados en el sector noroeste del afloramiento de rocas del Ordovícico a 1 y 1,3 km de MS1 respectivamente (Escola, Elías, Gasparotti y Sentinelli, 2015). Y uno más alejado a 2,2 km nombrado como el sitio Las Juntas, el cual presenta ocupaciones asignadas al primer y segundo milenio de la era (Escola et al., 2015). Por consiguiente, las inferencias cronológicas del uso de MS1 en base a la cercanía de otros sitios adscriptos a diversas cronologías generan altas incertidumbres. 
Las prospecciones realizadas en todo el sector de la red MS1 han brindado poca evidencia de material en superficie, solamente se han recolectado unos pocos fragmentos de cerámica condecoración estilo Belén. En la región esta decoración ha sido vinculada a momentos tardíos (posteriores a 1100 años AP) (Gasparotti, 2018). También la ausencia de instrumentos agrícolas, como fragmentos de palas y/o azadas líticas o cuchillos/ raederas de módulo grandísimo, es una particularidad sugerente. En la región los restos de palas y/o azadas líticas asociadas a tareas de labranza suelen ser muy abundantes en algunos sitios del Formativo (p. ej. Casa Chávez montículo) (Peréz, 2005), y tener baja frecuencias en el conjunto lítico de los sitios de adscripción tardía (p. ej. La Alumbrera, Bajo de Coypar II) (Elías, 2017). Principalmente, para los sitios ubicados en el fondo de cuenca, estas diferencias han sido atribuidas a cambios en los hábitos técnicos a partir de los 1100 años AP (Elías, 2017).

Por otro lado, MS1 presenta una similar distribución y organización espacial que la red de riego Los Colorados (Canal D), donde se registra el uso de bordos como tecnología agrícola, canales excavados y orientados en dirección logitudinal a un faldeo (Salminci et al., 2014). Esta red está asociada al sitio tardío Bajo de Coypar II, que cuenta con dataciones que van desde $1090 \pm 60$ a $670 \pm 60$ años AP y se encuentra a $10 \mathrm{~km}$ al sur, cerca de la confluencia del río Punilla y el río Colorado en el fondo de cuenca (Salminci, 2012).

Si bien hasta el momento, las evidencias cronológicas para esta red son mínimas y tienen un alto grado de incertidumbre, sólo se pueden generar hipótesis para exploraciones futuras. Excavaciones pendientes en sectores puntuales de la red (p. ej. sedimentos de la represas, sondeos en los refugios) permitirá brindar mayor exactitud sobre la cronología. Por el momento, a modo de hipótesis podríamos postular que la red habría tenido un posible funcionamiento durante el periodo Tardío (posteriormente a ca. 1100-1000 años AP).

\section{Consideraciones finales}

A modo de conclusión, este trabajo constituye una primera aproximación al estudio de las redes de riego en sectores particulares de la microrregión de Antofagasta de la Sierra. La aplicación de una metodología específica permitió generar nueva información sobre el diseño y la extensión de las redes de riego prehispánicas en la región. Definitivamente la extensión y complejidad de los mecanismos de riego, incluyendo la construcción de una represa, nos obligan a repensar el rol de estos sectores en la cartografía social agropastoril de Antofagasta de la Sierra. Y sobre la importancia de estas tecnologías como estrategias sociales en estos ambientes áridos puneños para contrarrestar la escases de agua. Creemos que, aunque este abordaje recién sea un comienzo, las investigaciones sobre redes de riego, su conformación y utilización, pueden ser la puerta para comprender la dinámica de las sociedades agropastoriles en la construcción de paisajes agrícolas y campesinos.

\section{Agradecimientos}

Queremos agradecer a la Dra. Patricia Escola por su lectura y sugerencias. A la Lic. Natalia Sentinelli y la Dra. Soledad Menéndez por su apoyo y colaboración en las tareas de campo. Al Dr. Pablo Tchilinguirian y al Dr. Daniel Olivera por la generosidad en compartir la información sobre el área.También agradecemos las observaciones de los evaluadores anónimos, que han permitido enriquecer y mejorar el trabajo. Por último, queremos dedicar esta investigación a la memoria del Dr. Pedro Salminci, por su enorme aporte al conocimiento sobre la agricultura de Antofagasta de la Sierra y su calidad como investigador, colega y amigo. 


\section{Q Referencias citadas}

》 Albeck, M. E. (1993). Contribución al estudio de los sistemas agrícolas prehispánicos de Casabindo (Puna de Jujuy). (Tesis Doctoral inédita), Universidad Nacional de la Plata, Argentina.

" Albeck, M. E. (2011). Estudios sobre agricultura prehispánica en Casabindo (1980-1993). En A. Korstanje y M. Quesada (Eds.), Arqueología de la agricultura. Casos de estudio en la región andina (pp. 6-47). Tucumán: Ediciones Magna.

» Albeck, M. E. y Scattolin, M. C. (1984). Análisis preliminar de los asentamientos prehispánicos de Laguna Blanca (Catamarca) mediante el uso de la fotografía aérea. Revista del Museo de La Plata (Nueva Serie), VIII, 279-302.

» Babot, M. (2006). El papel de la molienda en la transición hacia la producción agropastoril: un análisis desde la Puna Meridional Argentina. Estudios Atacameños, 32, 75-92.

" Barceló, M. (1996). El diseño de los espacios irrigados en al-Andalus: un enunciado de principios generales. En M. Barceló, H. Kirchner y C. Navarro (Eds.), El agua que no duerme. Fundamentos de la arqueología hidráulica andalusí (pp. 49-71). Granada: Fundación El legado andalusì.

»Cremonte, M. B. (1988). Alcances y Objetivos de los estudios tecnológicos en la Cerámica Arqueológica. Anales de Arqueología y Etnología, 38, 179-217.

" Díaz, R. (2009). Historias de Agua y Tierra: Introducción a los espacios agrícolas prehispánicos de Laguna Blanca. El caso de estudio de la Aldea Arqueológica Piedra Negra (Departamento Belén-Provincia de Catamarca). (Tesis de Licenciatura inédita), Universidad Nacional de Catamarca, Argentina.

»Elías, A. (2017). La Alumbrera y Campo Cortaderas: Contribuciones desde las Técnicas Líticas a la Complejidad Social, Política y Económica Tardía en Antofagasta de la Sierra. Andes, 28(1), 1-31.

"Escola, P. S., López Campeny, M. S., Martel, A., Romano, A., Hocsman, S. y Somonte, C. (2013). Re-conociendo un paisaje. Prospecciones en la Quebrada de Miriguaca (Antofagasta de la Sierra, Catamarca). Andes, 24, 397-423.

"Escola, P. S., Elías, A., Gasparotti, L. y Sentinelli, N. (2015). Quebrada del río Miriguaca (Antofagasta de la Sierra, Puna meridional argentina): nuevos resultados de recientes prospecciones. Intersecciones en Antropología, 16, 383-396.

"Farrington, I. S. (1980). The archaeology of irrigation canals, with special reference to Peru. World Archaeology, 11, 287-305.

» García, S., Rolandi, D. López, M. y Valeri, P. (2002). Alfa, vega y hortaliza. Riego y siembra en Antofagasta de la Sierra, Puna Catamarqueña. Relaciones de la Sociedad Argentina de Antropología, XXVII, 79-100.

》Gasparotti, L. (2015). Tecnología cerámica durante el Período Tardío en Antofagasta de la Sierra (Prov. de Catamarca). Una visión a través de cadenas operativas. Cuadernos de la Facultad de Humanidades y Ciencias Sociales, 48, 127-142.

" Gasparotti, L. (2018). Tecnología cerámica a lo largo del tiempo (ca. 2.000-500 años AP) en Antofagasta de la Sierra. Puna meridional Argentina. Aportes desde la petrografía cerámica. (Tesis Doctoral inédita), Universidad Nacional de Córdoba, Argentina.

"Gasparotti, L. y Escola, P. (2012). Elecciones tecnológicas en la alfarería. Abordaje preliminar de la cerámica de Corral Alto, Antofagasta de la Sierra (Catamarca). La Zaranda de Ideas. Revista de Jóvenes Investigadores en Arqueología, 8(1), 49-64. 
» Grana, L., Cohen, M. L. y Maidana, N. (2014). Methodological proposal to identify irrigation canals using diatoms as biomarkers: Peñas Coloradas (Antofagasta de la Sierra, Southern Puna Argentina). En D. Kligman y M. Morales (Eds.), Physical, Chemical and Biological Proxies in Argentina Archaeology: Theory, Methods and Applications (pp. 74- 86). Oxford: BAR.

» Grana, L., Tchilinguirian, P., Olivera, D., Laprida, C. y Maidana, N. (2016). Síntesis paleoambiental en Antofagasta de la Sierra: Heterogeneidad ambiental y ocupaciones humanas en los últimos 7200 años AP. Intersecciones de Antropología, 17(4), 19-32.

» Grant, J. (2014). Manejo económico de camélidos en Antofagasta de la Sierra (Puna Meridional Argentina): una aproximación zooarqueológica e isotópica. (Tesis Doctoral inédita), Universidad de Buenos Aires, Argentina.

» Killian Galván, V. A., y Salminci, P. (2014). Aportes a la ecología isotópica: información actual y sistemas de regadío arqueológicos en la microrregión de Antofagasta de la Sierra (provincia de Catamarca, Argentina). Comechingonia. Revista de Arqueología, 18(1), $51-72$.

» Kirchner, H. y Navarro, C. (1996). Objetivos, métodos y práctica de la arqueología hidráulica. En M. Barceló, H. Kirchner y C. Navarro (Eds.), El agua que no duerme. Fundamentos de la arqueología hidráulica andalusí (pp. 89-118). Granada: Fundación El legado andalusì.

» Korstanje, M. A., Cuenya, P. y William, V. (2010). Taming the control of chronology in ancient agricultural structures in the Calchaqui Valley, Argentina. Non-traditional data sets. Journal of Archaeological Science, 37, 343-349.

» Krapovickas, P. (1984). La economía prehistórica de la Puna. Runa. Archivo para las Ciencias del Hombre, XIV, 107-121.

» Krapovickas, P., Castro, A. S. y Meroni, M. (1980). La agricultura prehispánica en la Puna. En Actas del V Congreso Nacional de Arqueología Argentina, Tomo I (pp. 139-156). San Juan.

" Lane, K. (2009). Engineered highlands: The social organisation of water in the Ancient North-central Andes (AD 1000-1480). World Archaeology, 41(1), 169-190.

"Lanzelotti, S. (2011). Indicadores para el reconocimiento de represas arqueológicas. Relaciones de la Sociedad Argentina de Antropología, XXXVI, 177-196.

» Martínez, G. (1987). Para una etnografía de riego en Chiapa. Medidas de calendario. Chungará, 19, 163-179.

»Oliszewski, N. y Olivera, D. (2009). Variabilidad racial de macrorrestos arqueológicos de Zea mays (poaceae) y sus relaciones con el proceso agropastoril en la puna meridional argentina (Antofagasta de la Sierra, Catamarca). Darwiniana, 47(1), 76-91.

» Olivera, D. (1992) Tecnología y estrategias de adaptación en el Formativo (Agro-Alfarero Temprano) de la Puna Meridional Argentina. Un caso de estudio: Antofagasta de la Sierra (pcia. de Catamarca, R.A.). (Tesis Doctoral inédita), Universidad Nacional de la Plata, Argentina.

» Olivera, D. y Vigliani, S. (2000-2002). Proceso cultural, uso del espacio y producción agrícola en la puna meridional argentina. Cuadernos del Instituto Nacional de Antropología y Pensamiento Latinoamericano, 19, 459-481.

»Ortloff, C.E. (2009). Water Engineering in the Ancient World. Oxford: Oxford University Press.

» Orton, C., Tyres, P. y Vince, A. (1997). La Cerámica en Arqueología. Barcelona: Crítica.

»Ottonello de García Reinoso, M. (1973). Instalación economía y cambio cultural en el sitio tardío de Agua Caliente de Rachaite. Publicaciones de la Dirección de Antropología e Historia de Jujuy, 1, 23-68. 
»Pérez, M. I. (2013). Investigación sobre el Período Tardío-Inca en las localidades arqueológicas de Antofagasta de la Sierra (Puna Sur) y Cuenca del río Doncellas (Puna Norte): una aproximación a través de la cerámica. (Tesis Doctoral inédita), Universidad Nacional de Buenos Aires, Argentina.

»Pérez, S. (2005). Análisis de microdesgaste por uso de palas y/o azadas líticas de Antofagasta de la Sierra (Pcia. De Catamarca). Aportes para su interpretación funcional. Hombre y Desierto: Una perspectiva cultural, 12, 23-46.

»Purdue, L. y Berger, J. (2015). An integrated socio-environmental approach to the study of ancient water systems: The case of prehistoric Hohokam irrigation systems in semi-arid central Arizona, USA. Journal of Archaeological Science, 53, 586-603.

»Quesada, M. (2001). Tecnología agrícola y producción campesina en la Puna de Atacama, I milenio d.C. (Tesis de Licenciatura inédita), Universidad Nacional de Catamarca, Argentina.

"Quesada, M. (2007). Paisajes Agrarios en el Área de Antofalla. Procesos de Trabajo y Escalas Sociales de la Producción Agrícola. I y II Milenios d.C. (Tesis Doctoral Inédita), Universidad Nacional de La Plata, Argentina.

»Quesada, M. (2011). Agricultura campesina en el área de Antofalla (1997-2007). En A. Korstanje y M. Quesada (Eds.), Arqueología de la Agricultura. Casos de estudio en la región andina argentina (pp. 76-103). Tucumán: Ediciones Magna.

»Raffino, R. (1972). Las sociedades agrícolas del período tardío en la Quebrada del Toro y aledaños. Revista del Museo Nacional de La Plata (Nueva Serie), VII(45), 157-210.

» Rye, O. (1988 [1981]). Pottery Technology.Principles and Reconstruction. Manuals on archaeology, 4. Australian National University. Washington: Taraxacum.

»Salminci, P. (2012). Espacios residenciales y productivos. El paisaje arqueológico de Antofagasta de la Sierra entre los Siglos XI y XVI d.C. (Tesis Doctoral inédita), Universidad de Buenos Aires, Argentina.

» Salminci, P., Tchilinguirian, P. y Lane, K. (2014). Bordos and Boundaries: Sustainable Agriculture in the High Altitude Deserts of Northwest Argentina, AD 850-1532. Journal of Anthropological Archaeology, 2, 189-218.

» Santoro, C. M., Núñez, L. A., Standen, V. G., González, H., Marquet, P. A. y Torres, A. H. (1998). Proyectos de irrigación y la fertilización del desierto. Estudios Atacameños, 16, 321336.

»Scattolin, M. C. (2007). Un examen del espacio residencial y productivo en el Aconquija. Shincal, 7, 135-149.

»Sinópoli, C. (1991). Approaches to Archaeological Ceramics. Nueva York: Plenum Press.

»Skibo, J. (1992). Pottery Function: A Use-alteration Perspective. Nueva York: Plenum Press.

» Tchilnguirian, P. (2009). Paleoambientes Holocenos en la Puna Austral (27`S): implicancias geoarqueológicas, Argentina. (Tesis Doctoral inédita). Universidad de Buenos Aires, Argentina.

» Tchilnguirian, P. y Olivera, D. (2011). Aportes edafológicos para el estudio de campos agrícolas prehispánicos Bajo del Coypar, provincia de Catamarca. Cuaternario y Ciencias Ambientales, 4, 51-56.

»Wyndeldt, F. (2009). La Loma de los Antiguos de Azampay: un sitio defensivo del Valle de Hualfín (Catamarca, Argentina). Buenos Aires: Sociedad Argentina de Antropología.

»Zagodorny, N. (2000). Descripción de una técnica expeditiva de análisis cerámico. Contribución Arqueológica, 5, 259-266. 